\title{
Stock Market Reactions and CSR Disclosure in the Context of Negative CSR Events
}

\author{
Katrin Hummel ${ }^{*}$ \\ Department of Business Administration \\ University of Zurich \\ Affolternstrasse 56 \\ 8050 Zurich, Switzerland \\ E-mail: katrin.hummel@,business.uzh.ch \\ Stéphanie Mittelbach-Hörmanseder* \\ Department of Accounting, Finance \& Statistics \\ Institute for Accounting \& Auditing \\ WU Vienna, Welthandelsplatz 2 \\ 1020 Vienna, Austria \\ Email: stephanie.mittelbach-hoermanseder@wu.ac.at \\ Margarethe Rammerstorfer* \\ Department of Accounting, Finance \& Statistics \\ Institute for Finance, Banking and Insurance \\ WU Vienna, Welthandelsplatz 2 \\ 1020 Vienna, Austria \\ Email: margarethe.rammerstorfer@wu.ac.at \\ Karl Weinmayer* \\ MODUL University \\ 1190 Vienna, Austria \\ Email: karl.weinmayer@wu.ac.at
}

September 2019

\footnotetext{
* Author names listed in alphabetical order
} 


\title{
Stock Market Reactions and CSR Disclosure in the Context of Negative CSR Events
}

\begin{abstract}
This paper analyses stock market reactions after the occurrence of major negative corporate social responsibility (CSR) events and the possibility of mitigating these effects through the upfront provision of CSR information in firms' annual reports. For this purpose, we follow a three-step procedure. First, we analyse the major concerns gathered from REPRisk ${ }^{\circledR}$ data via event study analysis. Herein, we cover a window of 5 to 20 days. Second, we analyse all annual reports of the firms mentioned in the covered period over the entire time horizon and conduct a textual analysis to examine firms' disclosure of CSR information. Finally, we draw conclusions from the two approaches and show that firms with more upfront CSR information suffer from stronger negative market reactions after the occurrence of a negative CSR event. Herein, we show that if the occurrence of a negative CSR event conflicts with investors' expectations, then it leads to an important update of investors' beliefs about firms' prospects. Our results also confirm that such an event leads to an adjustment of the subsequent year's CSR disclosure in the annual reports.
\end{abstract}

JEL: G12, G14, G15, G24, M14, M41, D21, L21, D84

Keywords: Capital Markets, Corporate Social Responsibility, CSR disclosure, CSR event, Event Study, Textual Analysis, CSR Reporting, Shareholder Value 


\section{Introduction}

There is a substantial body of research that has investigated market reactions after the occurrence of critical events relating to corporate social responsibility (CSR). Examples of such events include waste mismanagement lawsuits (Muoghalu, Robison, and Glascock (1990), environmental crises and incidents (Klassen \& McLaughlin, 1996; Laplante \& Lanoie, 1994), chemical incidents (Blacconiere \& Patten, 1994; Capelle-Blancard \& Laguna, 2010), negative CSR events (Kruger, 2015), oil spills (Heflin \& Wallace, 2017), and human rights violations (Jacobs \& Singhal, 2017). Some of these studies focus on single incidents and examine intra-industry market reactions (Blacconiere \& Patten, 1994; Heflin \& Wallace, 2017). Other studies examine market reactions for a sample of different firms directly affected by the event (Kruger, 2015). Almost all of these studies tend to reveal negative market reactions following negative CSR-related events, thereby confirming that such incidents negatively affect investors' perceptions of future firm performance.

However, there has been relatively little research on the role of CSR disclosure in firms' annual reports in this setting. In this respect, Blacconiere and Patten (1994) examined the intra-industry market reactions following the Union Carbide chemical leak in Bhopal, India. They showed that firms with superior environmental disclosure prior to the chemical leak suffered less negative stock market reactions. Heflin and Wallace (2017) found similar findings in the context of the BP oil spill in the Gulf of Mexico in 2010. Their findings suggest that CSR disclosure increases investors' trust in a firm's ability to handle potential future consequences resulting from these intra-industry crises. Thus, firms can mitigate negative market reactions by demonstrating their superior CSR performance through increased disclosure before the occurrence of a negative event.

However, whether this finding also prevails for firms that are directly affected by a negative CSR event is both theoretically and empirically unclear. To put it more practically, is the decline in BP's stock price after the oil spill affected by the perception of BP's prior CSR disclosure? From a theoretical perspective, both directions are possible. On the one hand, the market might react less severely in the case of higher levels of CSR disclosure due to enhanced investors' trust in firms' handling of the catastrophe. On the other hand, since the occurrence of the negative CSR-related event is in sharp contrast to investors' expectations based on prior CSR disclosure, it might lead to an update of investors' beliefs about firms' prospects and thus sharper market reactions.

Against the background of these mixed theoretical predictions, our study provides further clarification on the role of CSR disclosure in the context of negative CSR-related events. Our sample comprises 1,581 negative CSR-related major events, retrieved from the REPRisk ${ }^{\circledR}$ database and categorized into environmental, social and corporate governance (ESG) events. First, we examine the stock market reactions following these events. Specifically, we refer to event study techniques and examine abnormal returns, as well as cumulative abnormal returns (CARs) and cumulative average abnormal returns 
(CAARs) around the events within certain topics. This research design is useful in overcoming endogeneity problems, particularly the issue of reverse causality. In addition, the staggered occurrence of such events mitigates the concerns that typically arise from single-event studies. Consistent with prior studies (e.g., Heflin \& Wallace, 2017; Kruger, 2015, etc.), we find significant negative abnormal returns following the occurrence of negative CSR-related events. Thus, investors react negatively to negative CSR events.

In a second step, we analyse whether there is a relationship between the (prior-event) extent of CSR disclosure in firms' annual reports and the market reactions following the event. We use textual analysis to measure the extent of CSR disclosure in a firm's annual reports. For this purpose, we draw on the methodology originally developed by Hoberg and Maksimovic (2014) and further refined by Hummel, Mittelbach-Hoermanseder, Cho, and Matten (2017) and examine the extent of disclosure of ESG issues in a firm's annual reports. Our results reveal negative correlations between a firm's extent of prior social and governance disclosure and the subsequent abnormal returns around the negative event. Thus, firms with more topic-specific CSR information prior to the event suffer stronger negative market reactions, which supports the second theoretical reasoning. This finding is contrary to those of Blacconiere and Patten (1994) and Heflin and Wallace (2017), thereby showing that only firms that are not directly affected by a negative CSR event, e.g., through an industry shock, can mitigate market reactions through prior disclosure. If the CSR event is firm-specific, it is in sharp contrast to investors' expectations (formed on the basis of prior disclosure), leading to an important update of investors' beliefs about firms' prospects. However, for environmental disclosure, we do not find significant correlations.

Third, we also examine the relationship between the abnormal returns following the event and CSR disclosure in the subsequent year. Such disclosure is useful for re-establishing investors' trust in firms' ability to handle the disaster. Consistent with this reasoning, prior studies document that intra-industry disclosure increases following the occurrence of a negative CSR-related event (Heflin \& Wallace, 2017; Patten, 1992). Our results not only document an increase in disclosure but also show that this increase is stronger for stronger negative market reactions. Thus, it appears that firms attempt to mitigate negative market reactions and re-establish trust among investors through increased CSR disclosure in subsequent years.

Overall, the contribution of this article is manifold. First, we support prior studies' findings by providing large-scale empirical evidence on the translation of CSR news into market reactions. Given the substantial negative market reactions that we document in our study, this finding provides a clear answer to the "does it pay to be green" question. Second, we discuss whether and how CSR disclosure affects market reactions by shaping investors' expectations. To the best of our knowledge, there are only two studies that link CSR disclosure to an event study of market reactions: that of Blacconiere and Patten (1994); and Heflin and Wallace (2017). While these studies focus on intra-industry reactions, our study complements the existing findings by focusing on firms that are directly affected by the (firm-specific) 
events. Third, we also expand the literature by showing not only that firms adapt their CSR disclosure after the occurrence of these events but that this adaption depends on the strength of prior market reactions. Regarding the practical contributions arising from our research, we would like to call the attention of firms to the importance of truthful and reasonable CSR disclosure. Specifically, we caution firms to create overly positive perceptions of their CSR performance through CSR disclosure since such a disclosure strategy can backfire in the case of the occurrence of a negative CSR event.

The paper is structured as follows: in Section 2, the theoretical background of our study is presented, along with our hypotheses. In Section 3, we introduce the research design, including the data, event study methodology, and our method for deriving textual variables from the annual reports via content analysis. Here, we focus on ESG issues. In Section 4, the results are presented, and their political and economic interpretations are discussed. Finally, Section 5 draws together the main findings and concludes the paper.

\section{Theoretical background and hypotheses}

\subsection{Market reactions to CSR events and concerns}

Several general articles focus on CSR activities or concerns that are directly announced through news channels. For example, Muoghalu et al. (1990) were the first to focus on environmental aspects, such as the impact of waste mismanagement lawsuits on stockholder returns, via the event study method. They show that in the case of a negative return because of a lawsuit, the profitability of waste mismanagement is reduced. Moreover, they detect a clear relationship between low penalties and incentives for the illegal disposal of waste. Furthermore, Laplante and Lanoie (1994) extend this approach by investigating whether shareholders' expectations are adjusted after similar environmental events. They distinguish between two different categories of events: "the announcement of environmental incidents likely to lead to a lawsuit" and "the announcement of investments in emissions control equipment." They find that the latter leads to a significant decrease in the equity value of the firms, whereas for lawsuits, the negative reaction accompanies the announcement of suit settlements and not the announcement of the lawsuits themselves per se.

Klassen and McLaughlin (1996) develop a theoretical model that describes the relation between environmental management and financial performance, which is tested via an event study. They find significant positive returns in the case of positive environmental events, such as winning performance awards, but significant negative returns, where there is weak environmental management during an environmental crisis. Additionally, Rao and Hamilton (1996) analyse the effect of ethics and profitability via a measure of environmental pollution. They find that firms with higher pollution show lower returns than expected from the asset-pricing model; thus, investors gain less than the expected risk adjusted rate of return. Blacconiere and Northcut (1997) analyse the stock market reaction towards 
the Superfund Amendments and Reauthorization Act in 1986. They find that the reaction is lower for firms with strong environmental disclosure, whereas "firms with greater exposure to Superfund costs" show a strong negative market reaction. In this context, Frooman (1997) and Endrikat (2016) provide a good overview of previous CSR event studies, encompassing 27 research articles up to 1997.

More recently, Karpoff, Lott, and Wehrly (2005) show that financial losses due to environmental events are primarily driven by legal and regulatory penalties and not, as often expected, affected by reputational losses. In their work, they confirm that environmental lawsuits accompany statistically significant losses in the market price of a firm, but these lawsuits are always in line with the legal penalties imposed. Capelle-Blancard and Laguna (2010) analyse serious chemical market incidents and their respective financial market reactions over a period ranging from 1990 to 2005. They find that in their sample, firms' market value drops by $1.3 \%$ during the first two days after the event, which increases with the seriousness of the accident.

Arya and Zhang (2009) analyse CSR announcements in the emerging stock market in South Africa between 1996 and 2005. They find that, in general, "CSR announcements of substantive monetary value result in significantly higher shareholder returns," which is especially expressed at the end of their considered time horizon. Groening and Kanuri (2013) analyse more than 1,000 positive and negative social events (e.g., the addition of strong retirement benefits for employees vs. employee health and safety concerns) via an event study. They do not find a consistent effect of positive or negative declared events, i.e., negative events can also bring about positive financial rewards, and vice versa. Thus, they conclude that stakeholder and shareholder perceptions are not necessarily the same. In the same year, Kölbel and Busch (2013) analyse the effects of negative news in related CSR topics on credit risk. For a sample of US and European firms, they show that negative media attention is associated with greater credit default swap spreads. Kruger (2015) focuses on both negative and positive CSR events (retrieved from the KLD database). Remarkably, Kruger (2015) shows that investors react negatively to both negative and positive CSR events. Recently, Jacobs and Singhal (2017) have analysed stock market reactions among Western textile retailers after the collapse of the Rana Plaza building in Bangladesh, which resulted in 1,133 deaths and 2,438 injured workers. Despite the devastating magnitude of the collapse, this event is not associated with significant direct costs for Western retailers due to the outsourcing of textile production. Nevertheless, the authors document weak negative stock market reactions for the event day, but these reactions subsequently dissipate.

Against the background of this strong empirical evidence, we argue that the occurrence of negative CSRrelated events negatively affects investors' perceptions of future firm performance. Such events typically imply significant immediate and future expenditures due to clean-up, warranty and compensation claims, investments for restoring reputation and customer trust, fines and future regulatory intensifications. Therefore, we formally posit the following hypothesis: 
H1. Firms that encounter a negative CSR-related event experience negative market reactions subsequent to the event.

\subsection{CSR disclosure as news and adjustments of disclosure because of news}

Voluntary disclosure theory suggests a positive relationship between CSR performance and CSR disclosure (Verrecchia, 1983). More precisely, it is argued that firms with superior CSR performance are incentivized to disclose CSR information to increase their market value. As a consequence, a considerable number of studies reveal positive relationships between (voluntary) CSR disclosure and firm value (Clarkson, Fang, Li, \& Richardson, 2013; D. Dhaliwal, Li, Tsang, \& Yang, 2014; D. S. Dhaliwal, Li, Tsang, \& Yang, 2011; Plumlee, Brown, Hayes, \& Marshall, 2015; Richardson \& Welker, 2001). Despite this substantial body of research on the relationships among CSR performance, CSR disclosure and firm value, relatively little is currently known about how firm-specific CSR events and their respective market reactions influence (firm-specific) CSR disclosure.

There is some empirical evidence revealing that firms can mitigate negative market reactions through CSR disclosure prior to the event. Among the first studies is that of Blacconiere and Patten (1994), who focus on Union Carbide's chemical leak in Bhopal (India) in 1984, which resulted in 4,000 deaths and 200,000 injuries. Blacconiere and Patten (1994) reveal significant negative intra-industry market reactions for chemical firms. These market reactions are less negative for firms with more extensive environmental disclosure prior to the event. The authors interpret their findings in a way that environmental disclosure increases investors' trust in firms' handling of future regulatory costs.

Similar findings are obtained by Heflin and Wallace (2017), who study the intra-industry market reactions of the BP oil spill in 2010. They show that firms with greater environmental disclosure are less affected by negative market reactions after the oil spill. The authors reason that investors perceive "firms with more environmental disclosure [to be] better prepared to address future environmental regulations and less likely to experience similar environmental incidents."

Taken together, the results of prior empirical studies tend to suggest that firms can mitigate negative market reactions following a negative CSR-related event through their prior-event CSR disclosure (Blacconiere \& Patten, 1994; Heflin \& Wallace, 2017). However, this finding is limited to intra-industry market reactions, i.e., the analysis is provided only for firms that are not directly involved in the event; thus, our article expands the current research state. We investigate the effects of firms being directly involved in an event. In general, firms' CSR disclosure should be aimed at maintaining or increasing investors' and stakeholders' trust. For firms with higher CSR intensity, Lins, Servaes, and Tamayo (2017) confirm that during the financial crisis of 2008 to 2009, the market reaction was lower for firms with higher CSR activities (measured using the MSCI ESG score). Thus, focusing only on CSR events, there are two possible relationships: on the one hand, one might argue that negative CSR events lead to negative effects caused by reputation loss or unfulfilled expectations with respect to the provided CSR 
disclosure, which is not reliable. However, on the other hand, it could be argued that if there is no clear negative financial effect in terms of fines or direct losses, this could lead to no market reaction; moreover, in the case of positive (prospective) future cash flows, positive abnormal returns also occur. Based on these opposing theoretical predictions and limited empirical evidence, we therefore posit a non-directional hypothesis:

H2: There is a relationship between firms' prior-event CSR disclosure and market reactions following the event.

In addition to their findings on the relationship between CSR disclosure and market reactions, Heflin and Wallace (2017) also document an increase in environmental disclosure in the year following the oil spill, particularly among firms with poor past environmental performance.

Such spillovers from the incident onto the disclosure in the consecutive year have already been documented by Patten (1992). The author investigates the environmental disclosure of petroleum firms after the Exxon Valdez oil spill. Patten (1992) also finds a significant increase in the environmental disclosure of the petroleum firms after the oil spill (excluding the disclosure of Exxon), although most of these firms are not directly involved in the oil spill.

More recently, Blanc, Branco, Cho, and Sopt (2013) investigate the CSR disclosure of the German multinational enterprise Siemens, which embraced a very large corruption scandal in 2006, over a period of eleven years. The authors find both symbolic and substantive actions in Siemens' CSR disclosure. In general, they report an increase in the disclosure of corruption directly after the event, which is followed by a continuous decrease in disclosure in the following years.

Thus, the empirical evidence suggests that the occurrence of a negative CSR-related event leads to increases in CSR disclosure in subsequent years. This evidence is found for both firms that are directly and not directly involved in the event (Blanc et al., 2013; Heflin \& Wallace, 2017). In the aftermath of a negative CSR event, firms attempt to maintain or re-establish investors' trust in their CSR performance through increased disclosure. ${ }^{1}$ The more severe (i.e., negative) the market reactions are that the firm experiences following the crisis, the stronger the incentives to re-establish investors' trust and thus the stronger the increase in disclosure. We therefore posit the following hypothesis:

H3: There is a negative relationship between market reactions following the event and firms' subsequent CSR disclosure. 


\section{Research design}

\subsection{Sample selection}

The event data, which are provided by REPRisk ${ }^{\circledR}$, covering the major concerns over the period 20112014, are gathered as the starting point of the analysis. More precisely, we refer to REPRISK $®$ "major controversies," i.e., the substantial negative ESG-related events covered in the REPRisk ${ }^{\circledR}$ database. By analysing each event in detail, they are manually attributed to one of the three ESG categories: environmental, social and governance.

Insert Table 1 about here

Panel A of Table 1 provides an overview of the events. As can be noted from Panel A, most events occur in 2012, while the lowest number of events occur in 2014. Regarding the classification of the events into the three main CSR categories - environmental (ENV), governance (GOV) and social (SOC) - most events belong to the social category $(n=830)$, followed by governance events $(n=393)$ and environmental events ( $\mathrm{n}=358)$. In total, 1,311 major events, caused by 618 firms, were collected between 2011 and 2014. After categorization into the abovementioned topics, we are left with a total of 1,581 events.

Recall that one firm can have more than one event occurring per period (year) and that deviations in the starting number of events to the categorized sum can occur. Furthermore, the number of event counts in a certain topic may be larger than the number of total events because one event can affect more than one of the three possible dimensions (environment, social, or governance). Panel B of Table 1 highlights some concerns exemplarily. Overall, for the hypothesis testing, the textual variables are important, and they are gathered by hand. Due to a lack of data availability, the textual variables after the event can be collected for 818 events, whereas for the textual variables prior to the event year, only 617 events can be considered.

\subsection{Event study methodology}

We follow the event study approach outlined by Brown and Warner (1985). To do so, we define the announcement day as the date on which news is released and denote it by day ${ }_{0}$ and the event period as a period consisting of 5,11, and 21 trading days, including the event day. Thus, the event period is denoted as ranging from day -1 to day +0 , day -5 to day +5 , day -10 to day +10 , or day -20 to day +20 . The observation period encompasses a total of 250 trading days ${ }^{2}$ for each company $i$ prior to the event, which is 
commonly referred to as the market model approach. For this approach, daily stock returns are used to run an OLS regression on the returns of a stock market index to estimate the model parameters $\alpha_{i}$ and $\beta_{i}$ :

$$
R_{i, t}=\alpha_{i}+\beta_{i} * R_{m, t}+\tilde{\epsilon}_{i, t}
$$

where

$$
\begin{aligned}
& R_{i, t}=\text { rate of return, company } i, \text { day }_{t}, \\
& R_{m, t}=\text { rate of return, stock market index } m, \text { day }_{t}, \\
& \alpha_{i}, \beta_{i}=\text { regression coefficients, company } i, \text { and } \\
& \tilde{\epsilon}_{i, t}=\text { error term, company } i, \text { day }_{t .}
\end{aligned}
$$

Following this approach, $\alpha_{i}$ and $\beta_{i}$ are then used to calculate expected returns $E R_{i, t}$ for each company $i$ and every day . $_{\text {. }}$

$$
E R_{i, t}=\alpha_{i}+\beta_{i} * R_{m, t}
$$

Following the approach of Eckbo (2007), a subtraction of the expected return from the actual return yields abnormal return $A R_{i t}$, which can be interpreted as being conditional on the event only and unconditional on market influences.

$$
A R_{i, t}=R_{i, t}-E R_{i, t}
$$

Furthermore, average abnormal returns from the event period are further aggregated over certain days (starting at $t 1$ through $t 2$ ) to compute a CAR $C A R_{(t 1, t 2)}$, as done by Halpern (1983). This allows for the detection of abnormal returns attributable to the announcement, even though they might have occurred right before the official announcement (e.g., due to information leaks or insider trading) or immediately after it (e.g., delayed publication of announcement). ${ }^{3}$

$$
C A R_{t 1, t 2}=\sum_{t=t 1}^{t 2} A R_{i, t t}
$$

For the event study, we refer to daily stock price data provided by Bloomberg for each firm that shows a certain event within the time period considered. The reference markets, i.e., the stock market index, is given by the largest index of the country in which the firm has its headquarters, i.e., firms from Germany are analysed with respect to the DAX, and US firms are analysed with respect to the S\&P 500. 


\subsection{Textual analysis and measures}

We use computer-assisted textual analysis to measure firm-specific CSR disclosure. Compared to traditional approaches for measuring CSR disclosure-such as content analysis and ratings from external data providers - textual analysis enables researchers to analyse large amounts of text based on objective and replicable techniques. With the increase in computing power, textual analysis is increasingly used in CSR disclosure research (Hummel \& Rotzel, 2019; Melloni, Caglio, \& Perego, 2017; Mittelbach-Hoermanseder, Hummel, \& Rammerstorfer, 2019; Muslu, Mutlu, Radhakrishnan, \& Tsang, 2019; Nazari, Hrazdil, \& Mahmoudian, 2017).

First, we collect the annual reports from each firm that experienced a negative CSR event for both the reporting period before and after the event (see figure 1). Thus, we include two subsequent annual reports. Next, we apply various pre-processing procedures to the text files to enhance the comparability of the text. ${ }^{4}$ We then construct topic-specific disclosure measures to assess the extent of CSR disclosure among the three categories, "environmental," "social" and "governance," according to a procedure that was first developed by Hoberg and Maksimovic (2014) and refined in the context of CSR disclosure by Hummel et al. (2017) and Hummel and Rotzel (2019). Our topic-specific disclosure measures are constructed as follows.

First, for each category, we define search terms to broadly capture the topic. More precisely, we search the reports for the occurrence of the words "ecology" for environmental disclosure, "social" for social disclosure and "governance" for governance disclosure. We then construct twenty word windows around the occurrence of the search terms in the reports. These word windows thus include the nine words preceding the search term, the search term and the ten words following the search term. We collect all twenty word windows to build a topic vocabulary for each search term. This reflects the topics more broadly than the search terms. Our topic-specific disclosure measures (discl_env, discl_social and discl_gov) are then calculated as the similarity between each report and the topic vocabularies. ${ }^{6}$ The scores range between 0 and 1 , with higher scores reflecting stronger similarity with the respective topicspecific vocabulary. Finally, based on the event date, the disclosure measures are divided into discl $_{P R I O R}$ and discl $_{P O S T}$, the former resulting from the analysis of the report published in the financial year prior to the event, namely, $t-1$, and the latter for the year of the event, corresponding to year $t$ (see figure 1).

Insert Figure 1 about here 


\subsection{Hypothesis testing}

For our first hypothesis on the market reactions to a negative CSR-related event, we use a simple t-test to test if the average abnormal return is significantly different from zero for each ESG category. The calculation of the abnormal return is described in Section 3.2.

To test our second hypothesis, we run the following regression for all ESG categories (environmental, social and governance) separately:

$$
A R_{i, t}=c+\operatorname{discl}_{P R I O R}+\operatorname{size},
$$

Size is measured as the natural logarithm of market capitalization. A negative coefficient for discl $_{P R I O R}$ indicates stronger market reactions for firms with more prior topic-specific CSR disclosure and thus a loss in trust of investors in the firm-specific CSR reporting with respect to the concerned category.

To test our third hypothesis, we run the following regression for each ESG category (environmental, social and governance) separately:

$$
\operatorname{discl}_{P O S T}=\mathrm{AR}_{\mathrm{i}, \mathrm{t}}+\text { size }+c .
$$

We expect a negative relationship, as the event may lead to an increase in reporting on the topic.

\section{Results}

\subsection{Descriptive statistics}

Table 2 provides an overview of the descriptive statistics for our disclosure measures and control variables. Consistent with the literature (Hummel et al., 2017; Hummel \& Rotzel, 2019), the mean values of the disclosure measures are rather low, thereby reflecting the low presence of these topics in firms' annual reports. As expected, the mean values for the discl $_{P O S T}$ measures are slightly larger than for the discl $_{\text {PRIOR }}$ measures. A comparison of the different ESG categories shows that the disclosure measures indicate the highest presence of governance topics among annual reports, followed by social topics and environmental topics.

Insert Table 2 about here 


\subsection{Results of hypothesis testing}

Table 3 displays the CAARs of all tested event windows for the events grouped along the three ESG categories as well as for a cumulative textual variable covering all three categories.

Insert Table 3 about here

On average, the abnormal returns are negative for all events. The significance is not that clear, as the different methods mentioned do not provide unambiguous results. Although the abnormal returns are on average negative, which is consistent with the negative characteristic of the concerns, the market does not react in only a negative way. This finding is consistent with other event studies, such as Kruger (2015). Specifically, some of the events are associated with positive abnormal returns and thus appear to be positively evaluated with regard to firms' future financial performance. Table 4 displays the descriptive statistics for the resulting abnormal returns up to 10 days prior and 10 days after the event. The table indicates that approximately 17 percent of the events have abnormal returns that are significantly different from zero on certain dates. As expected, we mainly reveal negative returns for the CSR-related events, which strongly supports hypothesis $\mathrm{H} 1$ and is consistent with the evidence of prior studies (Heflin \& Wallace, 2017; Kruger, 2015).

Insert Table 4 about here

Table 4 shows the results for all abnormal returns up to the maximum length of the 20-day event window. It presents the mean, median, maximum and minimum values, as well as the number of calculated abnormal returns over all events. The highest abnormal average return is observable for AR0; the longer the distance to the event day, the smaller the abnormal return becomes. Based on Table 4, we run OLS regressions on the abnormal returns of all days covered in the longest event period, with $+/-10$ days, as well as on CARs for all distinguished event windows. Table 5 outlines the results for the event date, as well as the CAR between the day prior the event and the event day itself. ${ }^{7}$

From hypothesis $H 2$, we examine whether firms with more topic-specific CSR disclosure prior to the event have different market reactions compared to firms with fewer CSR disclosures. These results are presented in Table 5. ${ }^{8}$ For social and governance events, we observe a negative and significant relationship between prior-event CSR disclosure and abnormal returns. This implies that firms with 
higher CSR disclosure before the event experience stronger negative market reactions. One potential explanation for this is linked to the trust of investors; it could be that investors have higher expectations towards firms with higher CSR disclosure to be better prepared for and less likely to experience a negative CSR event and thus more importantly update their expectations and beliefs about firms' prospects. This finding is contrary to those of Blacconiere and Patten (1994) and Heflin and Wallace (2017), but these studies focus on intra-industry market reactions and thus on firms that do not directly experience the negative CSR event. Our results therefore make a remarkable contribution to prior findings by revealing that CSR disclosure "shields" firms from negative market reactions only if they are not directly related to the event; if firms are directly affected by an event, the respective disclosure "damages" these firms. A possible explanation for this phenomenon could be that, when analysing industry-wide events, prior studies implicitly measure how companies are prepared to address broader future consequences resulting from the event. We, in contrast, investigate company-specific events and disclosure. The findings thus indicate the importance of firms aligning their CSR strategy, CSR performance and CSR disclosure and refraining from greenwashing. In line with Kruger (2015), we find a positive coefficient for firm size, suggesting that larger firms are in a better position than smaller firms to absorb negative news. ${ }^{9}$

Insert Table 5 about here

With regard to our last hypothesis, H3, the results are displayed in Table 6. For both social- and governance-related events, we find negative and significant coefficients for abnormal returns, thereby indicating that stronger negative market reactions are associated with greater post-event CSR disclosure. This finding is consistent with prior studies that document an increase in CSR disclosure after the occurrence of a negative CSR event (Blanc et al., 2013; Heflin \& Wallace, 2017; Patten, 1992). While prior studies mainly focus on firms in the same industry other than the directly affected firm, our results show that this relation holds not only for industry-wide shocks but also for firm-specific events. Thus, these firms attempt to re-establish investors' trust and confidence in their handling of the crisis through increased CSR disclosure. However, in connection with the results of $H 2$, confirming a negative relationship between abnormal returns and prior CSR disclosure, firms must be cautious because such a disclosure strategy may backfire in the case of subsequent CSR events.

Insert Table 6 about here 


\section{Conclusion}

This paper investigates the market reactions to firm-specific negative CSR events and the respective CSR disclosure, both before and after the occurring event. We focus on the reactions of both investors and the concerned firms. For the former, we analyse the relationship between prior-event CSR disclosure and market reactions; for the latter, we investigate how firms' CSR disclosure is affected by market reactions after the event. We apply an event study technique and focus on abnormal returns. For the measurement of CSR disclosure, we apply computer-assisted textual analysis and calculate similarity scores with respect to the three ESG categories (environmental, social and governance).

With respect to CSR disclosure, our results show that market reactions are stronger for firms with high levels of topic-specific CSR disclosure prior to the event. Thus, there seems to be an effect on the trust of investors, updating their expectations about future firm performance more importantly when prior topic-specific CSR disclosure is high. This finding complements prior findings in the literature, showing that firms that are not directly involved in the event but are affected because they are in the same industry and might face future regulatory actions can protect themselves from harsh market reactions through CSR disclosure. In our study, we focus only on firms that are directly involved in the CSR event, which drives the different findings of our study. In a next step, we investigate whether firms adjust their CSR disclosure after the event, and we find that the stronger the market reactions are, the stronger the increases in CSR disclosure after the event. This finding is consistent with those of prior studies, thereby indicating that both types of firms - those that are directly involved and those that are only indirectly involved-increase their CSR disclosure after the occurrence of an event. However, our results hold only for two of the three ESG categories-social and governance-related events. For the environment, we do not find any significance.

As with all studies, our study is subject to some limitations, which give rise to further research. First, the selection of events is based on the REPRisk ${ }^{\circledR}$ database. Although the database provides by far the most comprehensive overview of negative CSR-related events, we cannot rule out that the selection of events and, in particular, the classification into "major" events is biased towards certain firms or industries. Future studies might draw on other databases (such as the KLD database that is used by Kruger (2015)) and replicate our findings. Second, the typical criticism of the use of computer-assisted textual analysis applies. In particular, our measure of disclosure on ESG issues only broadly covers the extent of firm disclosure. Due to large differences in single events, we refrained from more granular topic-specific disclosure measures, which might be another avenue for future research. 


\section{References}

Arya, B., \& Zhang, G. (2009). Institutional Reforms and Investor Reactions to CSR Announcements: Evidence from an Emerging Economy. Journal of Management Studies, 46(7), 1089-1112. doi:10.1111/j.1467-6486.2009.00836.x

Blacconiere, W. G., \& Northcut, W. D. (1997). Environmental Information and Market Reactions to Environmental Legislation. Journal of Accounting, Auditing \& Finance, 12(2), 149-178. doi:10.1177/0148558X9701200203

Blacconiere, W. G., \& Patten, D. M. (1994). Environmental disclosures, regulatory costs, and changes in firm value. Journal of Accounting and Economics, 18(3), 357-377. doi:https://doi.org/10.1016/0165-4101(94)90026-4

Blanc, R., Branco, M. C., Cho, C. H., \& Sopt, J. (2013). In search of disclosure effects of the Siemens AG's corruption scandal. OBEGEF Working Papers, OBEGEF - Observatório de Economia e Gestão de Fraude, available at http://www.fep.up.pt/repec/por/obegef/files/wp015.pdf.

Brown, S. J., \& Warner, J. B. (1985). Using daily stock returns: The case of event studies. Journal of Financial Economics, 14(1), 3-31. doi:https://doi.org/10.1016/0304-405X(85)90042-X

Capelle-Blancard, G., \& Laguna, M.-A. (2010). How Does the Stock Market Respond to Chemical Disasters? Journal of Environmental Economics and Management, 59(2), 192-205. doi:http://www.sciencedirect.com/science/journal/00950696

Clarkson, P. M., Fang, X., Li, Y., \& Richardson, G. (2013). The relevance of environmental disclosures: Are such disclosures incrementally informative? Journal of Accounting and Public Policy, 32(5), 410-431. doi:https://doi.org/10.1016/j.jaccpubpol.2013.06.008

Dhaliwal, D., Li, O. Z., Tsang, A., \& Yang, Y. G. (2014). Corporate social responsibility disclosure and the cost of equity capital: The roles of stakeholder orientation and financial transparency. Journal of Accounting and Public Policy, 33(4), 328-355. doi:https://doi.org/10.1016/j.jaccpubpol.2014.04.006

Dhaliwal, D. S., Li, O. Z., Tsang, A., \& Yang, Y. G. (2011). Voluntary Nonfinancial Disclosure and the Cost of Equity Capital: The Initiation of Corporate Social Responsibility Reporting. The Accounting Review, 86(1), 59-100.

Eckbo, B. E. (Ed.) (2007). Handbook of corporate finance: empirical corporate finance (1. ed. ed. Vol. 1). Amsterdam: Elsevier [u.a.].

Endrikat, J. (2016). Market Reactions to Corporate Environmental Performance Related Events: A Meta-analytic Consolidation of the Empirical Evidence. Journal of Business Ethics, 138.

Frooman, J. (1997). Socially Irresponsible and Illegal Behavior and Shareholder Wealth: A MetaAnalysis of Event Studies. Business \& Society, 36(3), 221-249. doi: $10.1177 / 000765039703600302$

Groening, C., \& Kanuri, V. K. (2013). Investor reaction to positive and negative corporate social events. Journal of Business Research, 66(10), 1852-1860. doi:https://doi.org/10.1016/j.jbusres.2013.02.006

Halpern, P. (1983). Corporate Acquisitions: A Theory of Special Cases? A Review of Event Studies Applied to Acquisitions. The Journal of Finance, 38(2), 297-317. doi:10.2307/2327962

Heflin, F., \& Wallace, D. (2017). The BP Oil Spill: Shareholder Wealth Effects and Environmental Disclosures. Journal of Business Finance \& Accounting, 44(3-4), 337-374. doi:10.1111/jbfa. 12244

Hoberg, G., \& Maksimovic, V. (2014). Redefining Financial Constraints: A Text-Based Analysis. The Review of Financial Studies, 28(5), 1312-1352. doi:10.1093/rfs/hhu089

Hummel, K., Mittelbach-Hoermanseder, S., Cho, C., \& Matten, D. (2017). The Implicit versus Explicit Corporate Social Responsibility Disclosure: A Textual Analysis. working paper.

Hummel, K., \& Rotzel, P. (2019). Mandating the Sustainability Disclosure in Annual Reports--Evidence from the United Kingdom. Schmalenbach Business Review, 71(2), 205-247.

Jacobs, B. W., \& Singhal, V. R. (2017). The effect of the Rana Plaza disaster on shareholder wealth of retailers: Implications for sourcing strategies and supply chain governance. Journal of Operations Management, 49-51, 52-66. doi:https://doi.org/10.1016/j.jom.2017.01.002 
Jensen, M. C. (1986). Agency Costs of Free Cash Flow, Corporate Finance, and Takeovers. The American Economic Review, 76(2), 323-329.

Karpoff, Jonathan m., Lott, j. John r., \& Wehrly, Eric w. (2005). The Reputational Penalties for Environmental Violations: Empirical Evidence *. The Journal of Law \& Economics, 48, 675. doi:10.1086/430806

Klassen, R. D., \& McLaughlin, C. P. (1996). The Impact of Environmental Management on Firm Performance. Management Science, 42(8), 1199-1214.

Kolari, J. W., \& Pynnönen, S. (2010). Event Study Testing with Cross-sectional Correlation of Abnormal Returns. The Review of Financial Studies, 23(11), 3996-4025. doi:10.1093/rfs/hhq072

Kölbel, J., \& Busch, T. (2013). The effect of bad news on credit risk : a media based view of the pricing of corporate social responsibility: Amsterdam : Duisenberg School of Finance.

Kruger, P. (2015). Corporate Goodness and Shareholder Wealth. Journal of Financial Economics, 115(2), 304-329. doi:http://www.sciencedirect.com/science/journal/0304405X

Laplante, B., \& Lanoie, P. (1994). The Market Response to Environmental Incidents in Canada: A Theoretical and Empirical Analysis. Southern Economic Journal, 60(3), 657-672. doi:http://onlinelibrary.wiley.com/journal/10.1002/(ISSN)2325-8012

Lins, K. V., Servaes, H., \& Tamayo, A. (2017). Social capital, trust, and firm performance: The value of corporate social responsibility during the financial crisis. Journal of Finance, 72(4), 17851824.

Loughran, T., \& McDonald, B. (2016). Textual Analysis in Accounting and Finance: A survey. Journal of Accounting Research, 54(4), 1187-1230.

McDonald, B. (2016). Stop words list.

Melloni, G., Caglio, A., \& Perego, P. (2017). Saying more with less? Disclosure conciseness, completeness and balance in Integrated Reports. Journal of Accounting and Public Policy. doi:10.1016/j.jaccpubpol.2017.03.001

Mittelbach-Hoermanseder, S., Hummel, K., \& Rammerstorfer, M. (2019). Information Content of Corporate Social Responsibility Disclosures in Europe: An Institutional Perspective. Available at SSRN 3365521.

Muoghalu, M. I., Robison, H. D., \& Glascock, J. L. (1990). Hazardous Waste Lawsuits, Stockholder Returns, and Deterrence. Southern Economic Journal, 57(2), 357-370. doi:10.2307/1060617

Muslu, V., Mutlu, S., Radhakrishnan, S., \& Tsang, A. (2019). Corporate Social Responsibility Report Narratives and Analyst Forecast Accuracy. Journal of Business Ethics, 154. doi:10.1007/s10551-016-3429-7

Nazari, J. A., Hrazdil, K., \& Mahmoudian, F. (2017). Assessing social and environmental performance through narrative complexity in CSR reports. Journal of Contemporary Accounting \& Economics, 13(2), 166-178. doi:https://doi.org/10.1016/j.jcae.2017.05.002

Patell, J. M. (1976). Corporate Forecasts of Earnings Per Share and Stock Price Behavior: Empirical Tes. Journal of Accounting Research, 14.

Patten, D. M. (1992). Intra-industry environmental disclosures in response to the Alaskan oil spill: A note on legitimacy theory. Accounting, Organizations and Society, 17(5), 471-475. doi:https://doi.org/10.1016/0361-3682(92)90042-Q

Plumlee, M., Brown, D., Hayes, R. M., \& Marshall, R. S. (2015). Voluntary environmental disclosure quality and firm value: Further evidence. Journal of Accounting and Public Policy, 34(4), 336361. doi:https://doi.org/10.1016/j.jaccpubpol.2015.04.004

Rao, S. M., \& Hamilton, J. B. (1996). The Effect of Published Reports of Unethical Conduct on Stock Prices. Journal of Business Ethics, 15(12), 1321-1330.

Richardson, A. J., \& Welker, M. (2001). Social disclosure, financial disclosure and the cost of equity capital. Accounting, Organizations and Society, 26(7), 597-616. doi:https://doi.org/10.1016/S0361-3682(01)00025-3

Verrecchia, R. E. (1983). Discretionary disclosure. Journal of Accounting and Economics, 5, 179-194. doi:https://doi.org/10.1016/0165-4101(83)90011-3 
1 The results obtained by Heflin and Wallace (2017) suggest that this increase in disclosure reflects real improvements in firms' CSR performance and is thus not merely "window-dressing”.

2 A variation in the trading days between 120 and 250 days does not alter the results.

3 The abnormal returns of each individual company $i$ can also be aggregated over time (starting at $t 1$ through $t 2$ ) to compute the CARs $C_{A R s_{(t 1, t 2)}}$ for that company. These CARs within a certain topic can further be aggregated to CAARs.

4 These pre-processing procedures include the elimination of numbers, sample firm names and stop words (based on a word list provided by McDonald (2016) and the application of a stemming algorithm.

5 We also considered the term "environmental," but as our word lists reveals, the term is too broad in a company context.

${ }^{6}$ More precisely, the measure is calculated as the cosine similarity between a vector that reflects the frequency of words in firms' report and a vector that reflects the frequency of the words of the topic vocabulary. In addition, a term weighting procedure is incorporated (i.e., term frequency inverse document frequency (tfidf)) to adjust a word's weight based on

how (un)usual the word is (Loughran \& McDonald, 2016).

${ }^{7}$ All other days with abnormal returns or CARs reveal no significant results.

8 In line with Jensen (1986), we also used book leverage and liquidity as measures of agency concerns, but together with size, we do not find any significant relationship of these variables with the abnormal returns resulting from the RepRisk events.

9 Recall that the mainly negative sign allows for this conclusion. 


\section{TABLES}

Table 1 Overview of CSR-related concern

\begin{tabular}{|c|c|c|c|c|}
\hline Panel $A$ & & & & \\
\hline Year & Number of events & $E N V$ & GOV & $S O C$ \\
\hline 2011 & 435 & 120 & 82 & 233 \\
\hline 2012 & 518 & 131 & 140 & 247 \\
\hline 2013 & 394 & 78 & 107 & 209 \\
\hline 2014 & 234 & 29 & 64 & 141 \\
\hline Total & 1,581 & 358 & 393 & 830 \\
\hline No. of firms & 1,011 & 259 & 269 & 483 \\
\hline \multicolumn{5}{|l|}{ Panel B } \\
\hline Category & Date & Firm (ISIN) & Event & \\
\hline ENV, SOC & $29 / 01 / 2013$ & $\begin{array}{l}\text { Dana Gas PJSC } \\
\text { AED000701014 }\end{array}$ & \multicolumn{2}{|c|}{ Flooding of Egyptian village of Fares due to fracking } \\
\hline GOV & 03/07/2013 & $\begin{array}{l}\text { Royal Bank of } \\
\text { Canada } \\
\text { CA7800871021 }\end{array}$ & \multicolumn{2}{|l|}{ Manipulation of the Libor } \\
\hline $\mathrm{SOC}$ & $02 / 07 / 2013$ & $\begin{array}{c}\text { Daimler Car } \\
\text { DE0007100000 }\end{array}$ & \multicolumn{2}{|l|}{ Toxic car parts in Chinese cars } \\
\hline $\mathrm{SOC}$ & $18 / 11 / 2011$ & $\begin{array}{c}\text { Siemens AG } \\
\text { DE0007236101 }\end{array}$ & \multicolumn{2}{|c|}{ Supply of surveillance technology to repressive regimes } \\
\hline
\end{tabular}

Panel A of this table provides an overview of the event distribution per year and the respective number of firms. The number of firms and events may deviate, as one firm can have more than one event per period (year). Additionally, the number of event counts in a certain topic may be larger than the number of events, as events can affect more than one of the three possible dimensions (environment, governance, or social). Overall, without classification, we have 1,581 events that are further classified into one or more categories-social, governance or environmental. The events can be completely different in their severity, as outlined in Panel B, which highlights some concerns exemplarily. Therefore, we also expect that the outcome in terms of cumulative abnormal returns and abnormal returns may not be easily interpretable.

Table 2 Descriptive Statistics CSR disclosures

\begin{tabular}{|c|c|c|c|}
\hline & discl_env & discl_govPRIOR & discl_SOC $P R I O R$ \\
\hline Mean & 0.005316 & 0.050008 & 0.039682 \\
\hline Median & 0.003541 & 0.032246 & 0.032513 \\
\hline Maximum & 0.048570 & 0.241273 & 0.207151 \\
\hline Minimum & 0.000287 & 0.003985 & 0.003692 \\
\hline Std. Dev. & 0.005998 & 0.042751 & 0.027134 \\
\hline Skewness & 3.493801 & 1.511991 & 2.013273 \\
\hline Kurtosis & 18.38375 & 5.587212 & 9.020970 \\
\hline \multirow[t]{2}{*}{ Observations } & 585 & 585 & 585 \\
\hline & discl_env $v_{P O S T}$ & discl_gov ${ }_{P O S T}$ & discl_soc $P O S T$ \\
\hline Mean & 0.005464 & 0.050756 & 0.040526 \\
\hline Median & 0.003592 & 0.030371 & 0.032721 \\
\hline Maximum & 0.067782 & 0.249976 & 0.189041 \\
\hline Minimum & 0.000114 & 0.003985 & 0.002959 \\
\hline Std. Dev. & 0.006688 & 0.043548 & 0.029272 \\
\hline Skewness & 4.195902 & 1.396816 & 2.145306 \\
\hline Kurtosis & 27.16980 & 4.977154 & 9.177702 \\
\hline Observations & 770 & 770 & 770 \\
\hline
\end{tabular}

This table provides the descriptive statistics for the textual measures. 
Table 3 Cumulative abnormal results

\begin{tabular}{|c|c|c|c|c|c|c|}
\hline Environment & CAAR Type & CAAR Value & pos:neg CAR & No. of CARs & Patell Z & Adjusted Patell Z \\
\hline 5 Day & $(-2,2)$ & -0.0083 & $165: 193$ & 358 & -3.7838 & -3.8329 \\
\hline 10 Day & $(-5,5)$ & -0.0082 & $169: 189$ & 358 & -2.8075 & -2.844 \\
\hline 20 Day & $(-10,10)$ & -0.0177 & $168: 190$ & 358 & -4.5453 & -4.6044 \\
\hline \multicolumn{7}{|l|}{ Governance } \\
\hline 5 Day & $(-2,2)$ & -0.0017 & 199:194 & 393 & -0.5236 & -0.5137 \\
\hline 10 Day & $(-5,5)$ & -0.003 & $187: 206$ & 393 & -0.4827 & -0.4736 \\
\hline 20 Day & $(-10,10)$ & -0.0022 & $186: 207$ & 393 & -0.6487 & -0.6364 \\
\hline \multicolumn{7}{|l|}{ Social } \\
\hline 5 Day & $(-2,2)$ & 0.0089 & $398: 432$ & 830 & 2.7335 & 2.6536 \\
\hline 10 Day & $(-5,5)$ & -0.0062 & $405: 425$ & 830 & -3.0368 & -2.948 \\
\hline 20 Day & $(-10,10)$ & -0.0212 & $395: 435$ & 830 & -6.0294 & -5.8532 \\
\hline \multicolumn{7}{|l|}{ All } \\
\hline 5 Day & $(-2,2)$ & -0.0022 & $653: 712$ & 1365 & -2.9062 & -2.7369 \\
\hline 10 Day & $(-5,5)$ & -0.0016 & $655: 705$ & 1360 & -1.2066 & -1.0184 \\
\hline 20 Day & $(-10,10)$ & -0.0047 & 631:714 & 1345 & -3.1813 & -3.0901 \\
\hline
\end{tabular}

This table shows the cumulative average abnormal returns of all tested event windows for the negative events grouped into either the ESG categories or cumulated across all topics. The column CAAR Type indicates the window, CAAR Value, the CARs within a topic, and No. of CARs, the number of CARs considered, whereas the remaining columns provide different test statistics for testing whether the resulting CAARs are significantly different from zero $(H 0=C A A R=0)$. Herein, we distinguish Patell Z and Adjusted Patell Z, as suggested by Patell (1976) and Kolari and Pynnönen (2010), respectively. 
Table 4 Descriptive statistics of abnormal returns

Table $4^{1}$

Descriptive statistics of abnormal returns

\begin{tabular}{|c|c|c|c|c|c|c|c|c|c|c|c|}
\hline Day & -10 & -9 & -8 & -7 & -6 & -5 & -4 & -3 & -2 & -1 & 0 \\
\hline Mean & -0.000457 & -0.000593 & 0.000616 & -0.000152 & 0.000826 & -0.000275 & -0.000514 & -0.000382 & -0.000892 & -0.000506 & -0.001238 \\
\hline Median & -0.0003 & -0.0003 & 0.0002 & -0.0002 & 0.0002 & -0.0001 & -0.0002 & -0.0003 & -0.0002 & -0.0001 & -0.0006 \\
\hline Maximum & 0.1657 & 0.2331 & 0.1536 & 0.14 & 0.2445 & 0.1262 & 0.1324 & 0.2354 & 0.1815 & 0.4097 & 0.1453 \\
\hline Minimum & -0.2955 & -0.0939 & -0.2216 & -0.1424 & -0.1214 & -0.1321 & -0.1493 & -0.1199 & -0.2508 & -0.295 & -0.401 \\
\hline Std. Dev. & 0.019532 & 0.01813 & 0.017287 & 0.018213 & 0.018711 & 0.016662 & 0.016987 & 0.017565 & 0.020295 & 0.024108 & 0.023108 \\
\hline Observations & 1308 & 1303 & 1303 & 1308 & 1309 & 1309 & 1309 & 1304 & 1310 & 1308 & 1304 \\
\hline Day & & 1 & 2 & 3 & 4 & 5 & 6 & 7 & 8 & 9 & 10 \\
\hline Mean & & 0.000421 & -0.00066 & $3.23 \mathrm{E}-05$ & -0.000234 & 0.000269 & -0.000698 & -0.000103 & -0.000713 & $2.35 \mathrm{E}-05$ & 0.000107 \\
\hline Median & & 0.0002 & -0.0003 & 0.0001 & -0.00025 & -0.0003 & $-4.74 \mathrm{E}-05$ & -0.0004 & -0.0001 & 0.0001 & -0.0003 \\
\hline Maximum & & 0.2225 & 0.1682 & 0.1733 & 0.147 & 0.41 & 0.0997 & 0.2343 & 0.0916 & 0.4097 & 0.1515 \\
\hline Minimum & & -0.2495 & -0.1144 & -0.2215 & -0.1356 & -0.1733 & -0.401 & -0.248 & -0.2229 & -0.2036 & -0.198 \\
\hline Std. Dev. & & 0.020044 & 0.016392 & 0.0178 & 0.017776 & 0.019825 & 0.021718 & 0.01933 & 0.018017 & 0.020097 & 0.018272 \\
\hline Observations & & 1309 & 1304 & 1303 & 1304 & 1309 & 1310 & 1307 & 1306 & 1304 & 1306 \\
\hline
\end{tabular}

This table shows the results for all abnormal returns up to the maximum length of the 20-day event window. It presents the mean, median, maximum and minimum values, as well as the number of calculated abnormal returns over all events. 
Table 5

Prior-event CSR disclosure and abnormal returns

\begin{tabular}{|c|c|c|c|c|c|c|c|c|}
\hline \multirow{2}{*}{$\begin{array}{l}\text { Day } 0 \\
\text { Variable }\end{array}$} & \multicolumn{2}{|l|}{ Social } & \multicolumn{2}{|c|}{ Governance } & \multicolumn{2}{|c|}{ Ecology } & \multicolumn{2}{|l|}{ All } \\
\hline & Coefficient & Prob. & Coefficient & Prob. & Coefficient & Prob. & Coefficient & Prob. \\
\hline SIZE & $0.000873 * *$ & 0.0401 & $0.000774 *$ & 0.0683 & $0.000795 *$ & 0.0618 & $0.000805 *$ & 0.0578 \\
\hline $\operatorname{discl}_{P R I O R}$ & $-0.060493 * *$ & 0.0387 & $-0.031304 *$ & 0.0837 & -0.079113 & 0.5534 & $-0.070168 * *$ & 0.0457 \\
\hline$c$ & $-0.013061 *$ & 0.082 & -0.012144 & 0.1099 & $-0.013684 *$ & 0.0712 & -0.012024 & 0.1123 \\
\hline$R$-squared & 0.013474 & & 0.011289 & & 0.006782 & & 0.012995 & \\
\hline Adjusted R-squared & 0.010078 & & 0.007885 & & 0.003363 & & 0.009597 & \\
\hline S.E. of regression & 0.01883 & & 0.018851 & & 0.018894 & & 0.018835 & \\
\hline Sum squared resid. & 0.206015 & & 0.206471 & & 0.207412 & & 0.206115 & \\
\hline Log likelihood & 1492.655 & & 1492.009 & & 1490.681 & & 1492.513 & \\
\hline Durbin-Watson stat & 2.015536 & & 2.015595 & & 2.03272 & & 2.011496 & \\
\hline Observations & 584 & & 584 & & 584 & & 584 & \\
\hline \multirow[t]{2}{*}{ CAR $(\operatorname{day} 0+\operatorname{day}(-1))$} & \multicolumn{2}{|l|}{ Social } & \multicolumn{2}{|c|}{ Governance } & \multicolumn{2}{|c|}{ Ecology } & \multicolumn{2}{|l|}{ All } \\
\hline & Coefficient & Prob. & Coefficient & Prob. & Coefficient & Prob. & Coefficient & Prob. \\
\hline SIZE & $0.001312 * *$ & 0.0306 & $0.001163 *$ & 0.0552 & $0.001185 *$ & 0.0515 & $0.001206^{* *}$ & 0.0464 \\
\hline $\operatorname{discl}_{P R I O R}$ & $-0.100498 * *$ & 0.0173 & $-0.047344 *$ & 0.0711 & -0.116406 & 0.5461 & $-0.147069 * *$ & 0.0298 \\
\hline$c$ & $-0.019658 *$ & 0.0667 & $-0.018628 *$ & 0.0858 & $-0.020796 *$ & 0.0552 & $-0.018271 *$ & 0.0909 \\
\hline$R$-squared & 0.016396 & & 0.0123 & & 0.007359 & & 0.014789 & \\
\hline Adjusted $R$-squared & 0.013005 & & 0.008895 & & 0.003936 & & 0.011392 & \\
\hline S.E. of regression & 0.027166 & & 0.027222 & & 0.02729 & & 0.027188 & \\
\hline Sum squared resid & 0.428028 & & 0.42981 & & 0.431961 & & 0.428727 & \\
\hline Log likelihood & 1276.443 & & 1275.231 & & 1273.777 & & 1275.967 & \\
\hline F-statistic & 4.834226 & & 3.611558 & & 2.149825 & & 4.353195 & \\
\hline Prob. (F-statistic) & 0.008276 & & 0.027619 & & 0.117432 & & 0.013289 & \\
\hline Obs. & 584 & & 584 & & 584 & & 584 & \\
\hline
\end{tabular}

This table shows that there is a significant relationship between the abnormal return at day zero and the day before, caused by a certain concern and the CSR disclosure (textual analysis based on the report prior the event) prior the event. Coefficients and probabilities are given in columns two and three. ${ }^{* * *}, * *$, and $*$ indicate statistical significance at the 1\%, 5\% and $10 \%$ levels (two-tailed), respectively. 
Table 6 Regression Analysis Post Event

Table 6

Abnormal returns and post-event CSR disclosure

\begin{tabular}{|c|c|c|c|c|c|c|c|c|c|c|c|c|}
\hline \multirow{3}{*}{$\begin{array}{l}\text { Text Post } \\
\text { Variable } \\
\text { ARo }\end{array}$} & \multicolumn{3}{|c|}{ Social } & \multicolumn{3}{|c|}{ Governance } & \multicolumn{3}{|c|}{ Ecology } & \multicolumn{3}{|c|}{ All } \\
\hline & \multicolumn{2}{|c|}{ Coefficient } & \multirow{2}{*}{$\begin{array}{c}\text { Prob. } \\
0.0486\end{array}$} & \multicolumn{2}{|c|}{ Coefficient } & \multirow{2}{*}{$\begin{array}{c}\text { Prob. } \\
0.0541\end{array}$} & \multicolumn{2}{|c|}{ Coefficient } & \multirow{2}{*}{$\begin{array}{c}\text { Prob. } \\
0.7748\end{array}$} & \multicolumn{2}{|c|}{ Coefficient } & \multirow{2}{*}{$\begin{array}{l}\text { Prob. } \\
0.042\end{array}$} \\
\hline & -0.114542 & $* *$ & & -0.169559 & $* *$ & & -0.003587 & & & -0.095896 & $* *$ & \\
\hline SIZE & 0.000163 & & 0.7938 & -0.000915 & & 0.3332 & -0.000356 & $* * *$ & 0.0084 & -0.000369 & & 0.4657 \\
\hline$C$ & 0.037877 & $* * *$ & 0.0005 & 0.067611 & $* * *$ & 0 & 0.011553 & $* * *$ & 0 & 0.039014 & $* * *$ & 0 \\
\hline Observations & 770 & & & 770 & & & 770 & & & 770 & & \\
\hline$R$-squared & 0.005095 & & & 0.0063 & & & 0.009249 & & & 0.00628 & & \\
\hline Adjusted R-squared & 0.002501 & & & 0.003709 & & & 0.006666 & & & 0.003688 & & \\
\hline S.E. of regression & 0.029108 & & & 0.044129 & & & 0.006292 & & & 0.023635 & & \\
\hline Sum squared resid & 0.64984 & & & 1.493628 & & & 0.030369 & & & 0.428456 & & \\
\hline Log likelihood & 1632.224 & & & 1311.813 & & & 2811.59 & & & 1792.591 & & \\
\hline Durbin-Watson stat & 1.916817 & & & 2.011169 & & & 1.881242 & & & 1.951571 & & \\
\hline
\end{tabular}

This table shows the results for Hypothesis 3. Coefficients and according probabilities are given. . ***, **, and * indicate statistical significance at the $1 \%, 5 \%$ and $10 \%$ levels (two-tailed), respectively 